\title{
A Utilidade dos Diagramas de Lewis no Ensino da Química
}

\author{
VICTOR M.M. LOB O*
}

\section{Defende-se a utilidade \\ das fórmulas de estrufura \\ no ensino da química \\ e apresenta-se um modo \\ de o ensinar a nivel elementar.}

Palavras-chave: fórmulas, Lewis, moléculas, ensino.

\section{INTRODUÇÃO}

Constato que há um generalizado desconhecimento entre alunos que estudam ou estudaram química, e mesmo já profissionais a ensinar esta matéria, dos chamados "diagramas de Lewis" ou "fórmulas de estrutura". Por exemplo, nenhum dos meus cerca de trinta alunos de uma disciplina do final da licenciatura que prepara professores de Química e Física para o ensino secundário, era capaz de escrever mesmo as mais elementares fórmulas, e.g. do $\mathrm{NaCl}$. Nenhum fazia a mínima ideia dos pressupostos em que assenta o modelo, ou tinha a mais pequena ideia da enorme vantagem que tal escrita tem para a compreensão da química. Verifiquei isto este ano, e no passado ano, quando tomei conta desta disciplina. Verifico também que professores estagiários de Ciências FísicoQuímicas igualmente nada sabem, até que, chegando à altura de o ensinarem no ensino secundário, procuram estudar algo sobre o assunto, ficando, contudo, com umas ideias muito confusas. Praticamente, limitam-se a decorar as fórmulas de uns tantos compostos que depois escrevem no quadro (ou nos acetatos que projectam). Nenhum dos meus estagiários do ensino secundário deste ano foi capaz de escrever a fórmula do sulfureto de césio. Um, olhando demoradamente para a tabela periódica, escreveu

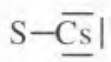

e nenhum dos outros foi capaz de comentar! Algo de similar se tem passado com alunos meus já do fim das respectivas licenciaturas em
"Electroquímica e Corrosão" ou "Corrosão" (Química e Química Industrial).

Contudo acredito que, com os devidos cuidados, este assunto pode ser ensinado logo no $3^{\circ}$ ciclo $\left(8^{\circ}\right.$ e $9^{\circ}$ anos), devendo depois ficar bem assente na mente dos alunos de química do $10^{\circ}$ ano, de tal modo que, daí em diante, seja uma "ferramenta" de uso permanente na compreensão da química.

Costumo dizer aos alunos que, em Química, quando se pensa em "água" ou "ácido sulfúrico", o que deve vir à mente não é $\mathrm{H}_{2} \mathrm{O}$, mas sim<smiles>O</smiles>

e não $\mathrm{H}_{2} \mathrm{SO}_{4}$, mas sim<smiles>O=[SH]([O-])(O)O</smiles>

Aliás, quando vejo a fórmula molecular de qualquer composto que desconheço, logo faço um esforço por visualizar a sua fórmula de estrutura. Sem isso, sinto que não "entendo" que composto é esse.

Não será assim que deve agir qualquer pessoa que tenha de lidar com Química? Pelo menos, quando lidei com disciplinas introdutórias à Química, insisti fortemente neste ponto. Eu próprio tive uma forte incidência nessa matéria na disciplina de "Química Inorgânica" do meu $1^{\circ}$ ano de Engenharia Química, dada pelo Grande Mestre [1], que tem sido e continua a ser, o Senhor Professor Doutor F. Pinto Coelho. Não se passava sem se saber isso muito bem. Nessa altura compreendia-se que os alunos chegassem à Universidade sem tal saberem, pois não era ensinado no liceu. Contudo, hoje, pelo menos formalmente, é-o. Só que, parece-me, não da melhor maneira. É nessa óptica que pretendo convidar os meus colegas do ensino secundário e superior a discutirem comigo sobre a validade dos pontos de vista que vou expor. Talvez o endereço do correio electrónico citado junto à direç̧ão postal seja o mais prático para tal.

Acredito que é possível dar uma imagem dos fundamentos das ideias de Lewis e Kossel (já maduras na década dos 1920's) logo a nível do $3^{\circ}$ ciclo, isto é, logo que se começa a pôr o problema de escrever reacções químicas, e portanto a ter de se saber algumas fórmulas moleculares. Deve minimizar-se o uso da memória para saber a estequiometria das fórmulas e o modelo assente nessas ideias pode, dentro de limites, ser uma ferramenta para o aluno saber que, e.g. o cloreto de cálcio é $\mathrm{CaCl}_{2}$, isto é, 1 : 2 , e não $1: 1,2: 2$, ou qualquer outra relação estequiométrica. Assim, logo que se falasse na constituição fundamental do átomo e na tabela periódica, podia-se avançar com o modelo para, a partir daí, o aluno se habituar a "construir" as moléculas, e não a "decorá-las".

Tento aqui expor um método para tal, baseado apenas no "átomo de Bohr" [2], no conceito de electrões do último nível energético, e na simplória "regra do octeto". Não uso vocábulos como "orbital", "valência", "electrões de valência", "nevoeiro electrónico", "electronegatividade", "afinidade electrónica", "energia de ionização", etc. O objectivo é a apresentação de um esquema de raciocínio simples mas efectivo (dentro de certos limites). o essencial é que o aluno pratique muito com este esquema, de tal modo a visualizá-lo rapidamente. Assim sendo, e já depois do $9^{\circ}$ ano (para os que seguirem para Ciências), o aluno facilmente compreenderia "aperfeiçoamentos" ao modelo, de modo a torná-lo mais abrangente e profundo. Também na Álgebra, o primeiro objectivo será (ou já nāo é?!!!!) o de ensinar a resolver equações do $1^{\circ}$ grau a uma incógnita, praticar muito essa resolução, e só depois é que se passaria para sistemas de $n$ equações de diversos graus a $\mathrm{n}$ incógnitas. Isto é, mandar fazer exercícios de construção de fórmulas de estrutura de, e.g. sulfureto 
de sódio, deveria ser o equivalente a mandar resolver uma equação, e.g. $3 x+5=7$. Um aluno de Ciências (Engenharias, etc.) que chegue à Universidade sem saber o primeiro, é como se também não soubesse resolver $3 x+5=7$. Mas pior é sairem duma licenciatura em Química sem ainda saber fazer a fórmula de estrutura do tal sulfureto de sódio!!!

Este tipo de matéria seria mesmo um bom caso para o professor mostrar bem aos alunos a diferença entre factos observados e teorias para os explicar, e prever novos factos (a confirmar pela experiência logo que possível). Aqui os factos são a nossa observação experimental das propriedades dos compostos (e.g. que o cloreto de sódio das salinas da Figueira da Foz é sólido, rijo, quebradiço, dissolve-se em água, etc.). sendo a sua constituição elementar conhecida através da análise química experimental (é daí que sabemos que é $\mathrm{NaCl}$, não é do modelo). A teoria, isto é, o modelo de raciocínio, é meramente um esquema que só está na nossa mente, mas tem a grande vantagem de prever que poderá haver uma "entidade"

$$
\mathrm{Na}+|\overline{\mathrm{Cl}}|-
$$

que assim deverá ser sólida, rija, quebradiça, e se deverá dissolver bem na água. E tal previsão até bate certo. Aqui talvez fosse útil dizer aos alunos que também há modelos que permitem fazer previsões metereológicas. Às vezes falham, mas nem por isso deixam de ser modelos muito úteis. Eu costumava usar a analogia dos manequins que exibem os fatos e vestidos nas montras: embora artificiais, conseguem formar na nossa mente uma imagem sobre o modo como a peça de roupa assenta no corpo humano. Também os diagramas de Lewis são "manequins", mas que podem dar uma ideia muito boa sobre as propriedades das moléculas que representam.

Levar alunos até ao fim do ensino secundário e, pior, duma licenciatura, sem essa ferramenta, é como levá-los sem serem capazes de resolver $3 x+5=7$ ou calcular a área de um triângulo! E parece que também já há queixas dessas lá pelas matemáticas!

\section{ESQUEMA DE ENSINO PARA NÍVEL ELEMENTAR}

A composição e a estrutura de um grande número dos compostos químicos existentes podem ter uma primeira interpretação com base num modelo simples assente nos seguintes pressupostos [3].

2.1. Um composto (uma molécula) tem alta estabilidade se cada átomo "tiver o octeto completo", isto é, se pudermos visualizar a sua estrutura de tal modo que cada átomo tenha oito electrões no seu último nível energético (ou dois para o $\mathrm{H} \mathrm{e}$ He). Este pressuposto pode ser denominado por "regra do octeto". Assim, os átomos $\mathrm{Ne}, \mathrm{Ar}, \mathrm{Kr}, \mathrm{Xe}, \mathrm{Rn}$, têm já de si o "octeto completo" e, por isso, não deverão ter tendência a associarse com quaisquer outros átomos, isto é, as suas moléculas deverão ser monoatómicas. Dada a pequenez das moléculas e a sua não tendência para qualquer outra associação, é de prever que um conjunto de moléculas daqueles elementos seja uma substância gasosa. A sua estrutura pode representar-se por

\section{$|\underline{\overline{N e}}||\underline{\overline{A r}}||\overline{\underline{K r}}||\underline{\overline{\mathrm{Xe}}}||\underline{\overline{\mathrm{Rn}}}|$}

onde um traço representa 2 electrões no último nível energético.

O hélio, He, tem também o último nível energético completo, embora só com 2 electrões, pelo que o "espírito" da regra do octeto é também satisfeito, e a sua estrutura será

\section{$\mathrm{IHe}$}

Como só para o He e o $\mathrm{H}$ a palavra "octeto" deveria ser, por rigor etimológico, substituída por algo como "dueto", seria inútil e criaria confusão tentar tal alteração do vocabulário, isto é, não há mal por se continuar a usar a palavra "octeto". Afinal a Ciência (ou a toponímia duma cidade) está cheia de vocábulos etimologicamente incorrectos. É o caso de átomo (o indivisível, e ele divide-se!), termodinâmica, etc., ou Pátio da Inquisição (e felizmente que já lá se não faz inquisição nenhuma!).

Uma comparação do previsto para os elementos do grupo 18 (VIII) da tabela periódica pelo presente modelo com a realidade experimental é até muito encorajadora para a utilidade de tal modelo. Efectivamente o He, Ne, Ar, Kr, Xe, Rn, são gases à temperatura ambiente, como previsto pelo modelo, verifica-se experimentalmente que são monoatómicos e que na natureza não há compostos estáveis em que aqueles elementos se associem a outros, tudo tal como previsto pelo modelo.

É certo que, no laboratório, e em condições de excitação altamente energética, é possível provocar artificialmente ligações daqueles átomos com outros. Mas tal, de maneira nenhuma, põe em causa a utilidade do modelo. Não nos esqueçamos que é um modelo, útil enquanto for capaz de prever um grande número de situações; não é uma "regra" que dite como é que a natureza "tem" de se comportar. De modo análogo, outros casos, alguns conhecidos como "excepções à regra do octeto", não retiram validade à utilização prática deste modelo.

2.2. A composição e a estrutura de compostos constituídos por elementos do grupo 1 (IA, metais alcalinos) e do 17 (VIIB, halogénios) podem ser interpretadas pressupondo que os primeiros "cedem" o electrão da sua última camada, ficando portanto com a anterior como última camada e, desta maneira, completa. O átomo do halogénio que, de 7 electrões na última camada passaria a ter $8, \operatorname{logo}$, o "octeto completo", também "obedece à regra do octeto". 
Exemplo:

De Na. e $\overline{\bar{C}}$ ll podemos imaginar a entidade

$$
\mathrm{Na}+|\overline{\mathrm{Cl}}|-
$$

donde se conclui que a fórmula molecular seria $\mathrm{NaCl}$. Compreendendo isto é fácil de ver que a estequiometria seria $1: 1$ e não $2: 1,1: 2,3: 2$, etc. Tal bate certo com o verificado experimentalmente, e este tipo de previsão é uma das facetas mais positivas deste modelo.

Note-se que se deve tornar bem claro que não há aqui nenhuma reacção química entre sódio e cloro. Há meramente um esquema mental com o objectivo de prever a fórmula molecular do composto e algumas das suas propriedades através destes simples diagramas. Assim, NUNCA se deve escrever algo como

$$
\mathrm{Na} \cdot+\cdot \underline{\overline{\mathrm{C}}}\left|\longrightarrow \mathrm{Na}^{+}\right| \underline{\overline{\mathrm{Cl}}} \mid-
$$

(NUNCA ISTO!)

ou qualquer outro simbolismo que leve o leitor a pensar que há ali qualquer formação de cloreto de sódio. Deve-se mostrar bem aos alunos que o sal se forma, e.g., nas salinas como as da Figueira da Foz sem que lá haja qualquer transferência de electrões!

A utilidade de imaginar o diagrama

$$
\mathrm{Na}+|\overline{\mathrm{Cl}}|-
$$

é, para além da previsão da estequiometria já citada, prever um pouco das suas propriedades. Assim, pode mostrar-se aos alunos que o composto deve ser um sólido, pois à unidade

$$
\mathrm{Na}+|\overline{\mathrm{Cl}}|-
$$

devem-se juntar outras tridimensionalmente (aqui mostrar-se-ia um modelo da estrutura do cloreto de sódio). Como a força que liga um $\mathrm{Na}^{+}$ao da direita, da esquerda, de cima ou de baixo, é igual, todo o conjunto é uma só "molécula" gigante, onde a entidade

$$
\mathrm{Na}+|\overline{\mathrm{Cl}}|-
$$

é somente a unidade de repetição (analogia com os padrões dos tecidos, ou qualquer outra). Então é fácil de prever que o tal composto, de "fórmula molecular" $\mathrm{NaCl}$, deve ser um sólido de estrutura difícil de deformar ou dobrar, embora "quebradiço". Mais tarde, tal imagem vai ser útil para interpretar a sua fácil solubilização num solvente polar como a água.

Mostrar-se-ia agora, exibindo alguns cristais de cloreto de sódio, como todas estas previsões se ajustam bastante bem à realidade experimental, dando por isso credibilidade à utilidade do modelo.

Uma vez entendido o modelo para o $\mathrm{NaCl}$ os alunos devem fazer vários exercícios, por enquanto só com metais alcalinos e halogénios, isto é, deve-lhes ser pedido que façam o diagrama de Lewis, e daí concluam a fórmula molecular de, e.g. brometo de potássio, fluoreto de césio, etc., garantindo que estas ideias básicas estejam bem entendidas. Só depois disso se passaria para associações de elementos do grupo 2 (IIA, alcalino-terrosos) com os do grupo 16 (VIB). Em seguida, ao mandarem-se fazer (como exercícios) exemplos de associações do grupo $2 \mathrm{com}$ o 17, ou do grupo 1 com o 16, dir-se-ia que, embora no papel não seja fácil representar com rigor a estrutura tridimensional da molécula, há maneiras mais plausíveis que outras de escrever a fórmula de Lewis. Assim, a um aluno que representasse o cloreto de cálcio como

$$
|\underline{\overline{\mathrm{Cl}}}|^{-}|\underline{\overline{\mathrm{Cl}}}|^{-} \mathrm{Ca} 2+
$$

dir-se-ia que seria melhor que escrevesse

$$
|\underline{\overline{\mathrm{Cl}}}|^{-} \mathrm{Ca}^{2}+|\underline{\overline{\mathrm{C}}}|^{-}
$$

pois é óbvio que tal se aproximará mais da realidade.

Talvez fosse agora a altura para "apresentar" aos alunos o hidrogénio, H, não como tendo um só electrão no último nível, mas como lhe faltando um para o completar, isto é, como se na tabela periódica estivesse acima do flúor e não acima do lítio (aliás até há autores de tabelas periódicas que assim fazem). Assim, mandava-se fazer a fórmula de estrutura, e daí concluirem a molecular, de compostos como hidreto de lítio (hoje tão útil para pilhas), de cálcio, etc.

Ensinar-se-ia que este tipo de ligação química é conhecido por "ligação iónica".

2.3. Reconheço que não será tão fácil apresentar aos alunos a ligação covalente como terá sido a iónica! Mas os jovens estão muito abertos à imaginação, e com algum jeito e apelos ao artificialismo dos modelos (contudo de grande utilidade), lá irão certamente entender o raciocínio que nos conduz à composição e estrutura de moléculas só formadas por átomos que já têm o octeto quase completo.

o exemplo mais conveniente para a introdução do conceito seria o

\section{$\underline{\mid \overline{\mathrm{Cl}}}$.}

mostrando-se que na entidade

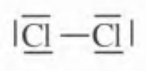

consideramos haver dois electrões que pertencem a ambos os átomos, que são a ligação entre eles (chamemos-lhe "ligação covalente"), e que, com este raciocínio, cada átomo tem o "octeto completo". É fácil de mostrar que a atomicidade deverá ser 2 e não 3, etc.

No caso dos átomos que "recebem" electrões, defendo que se devem treinar os alunos a indicar sempre todos os electrões da última camada, isto é, escrever-se sempre 


\section{$|\underline{\overline{\mathrm{Cl}}}-\underline{\overline{\mathrm{Cl}}}|$ e não $\mathrm{Cl}-\mathrm{Cl}$}

ou<smiles>O</smiles>

ou<smiles>CC(=O)O</smiles>

e não<smiles>CC(=O)O</smiles>

É evidente que quando se presume que o leitor percebe muito bem o assunto (caso de livros a nível universitário), os autores já não têm tal preocupação. Defendo também que, a nível elementar, um traço queira simplesmente dizer o mesmo que dois pontos (ou duas cruzes). A nível mais avançado far-se-ia a devida diferença. Por razões gráficas é mais conveniente usar traços (para cada dois electrões) do que pontos, ou cruzes. Para um só electrão é indiferente usar um ponto ou uma cruz, o que poderá depender da facilidade de os mostrar no texto impresso, ou de os desenhar manualmente no papel ou no quadro.

Após muitos exercícios com elementos dos grupos 17 e 16 (incluindo $\mathrm{o} \cdot \mathrm{H}$, sempre considerado como faltando-lhe um electrão para ter o último nível completo), passar-se-ia ao grupo 15, e daí às fórmulas dos importantíssimos compostos $\mathrm{N}_{2} \mathrm{e}$ $\mathrm{NH}_{3}$ e depois aos perigosos $\mathrm{PH}_{3} \mathrm{e}$ $\mathrm{AsH}_{3}$. Passar-se-ia seguidamente ao carbono, daí ao $\mathrm{CH}_{4}$, isto é, "abria-se a porta" para a química orgânica, ou melhor, química dos compostos de carbono, "brincando" com as fórmulas de Lewis de hidrocarbonetos como os da gasolina, ácidos e alcoóis como o acético e etílico, etc.

Após muitos exercícios com estes compostos só de 2 átomos diferentes, passar-se-ia a casos mais complexos, mas sempre "obedecendo à regra do octeto", talvez começando pela série $\mathrm{HCl}, \mathrm{HClO}, \mathrm{HClO}_{2}$,

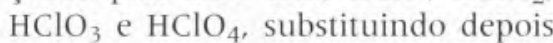
o $\mathrm{Cl}$ pelos outros halogénios. Seguirse-iam moléculas como $\mathrm{H}_{2} \mathrm{SO}_{3}$, $\mathrm{H}_{2} \mathrm{SO}_{4}, \mathrm{SO}_{2}, \mathrm{HNO}_{3}, \mathrm{H}_{3} \mathrm{PO}_{4}$. Posteriormente considerava-se a "substituição" do $\mathrm{H}$ por átomos dos grupos 1 e 2, e.g. $\mathrm{KClO}_{4}$ ou $\mathrm{CaSO}_{4}$. Também só a nível posterior se introduziria o "problema" dos "electrões do último nível" dos metais de transição.

Quanto à divisão entre os átomos da "esquerda" e da "direita" da tabela periódica, isto é, os que "cedem" e os que "recebem" electrões, parece-me que não haveria mal em tomar-se a divisória entre $\mathrm{Be} /, \mathrm{B}, \mathrm{Al} / \mathrm{Si}, \mathrm{Ge} / \mathrm{As}, \mathrm{Sb} / \mathrm{Te}, \mathrm{Po} / \mathrm{At}$, frequentemente representada nas tabelas periódicas (e.g. as de Sargent Welsh) com uma linha quebrada mais cheia, como a linha que os separaria. Por outras palavras, ensinar-se-ia simplesmente que ligações dos à esquerda dessa linha com os à direita, são iónicas; ligações só com os à direita dessa linha são covalentes; ligações só com os à esquerda dessa linha são metálicas (abaixo discutidas).

Como se vê, foi sempre possível não usar vocábulos como "electronegatividade", "orbital", etc. Devem, certamente, ser ensinados, mas mais tarde, só depois de o aluno ter feito muitos exercícios, a ponto de fazer a estrutura, e.g. do hidreto de potássio, com a mesma facilidade com que resolve a equação $3 x+5=7$. Aparecem-me alunos vindos do ensino secundário a falar em orbitais ligantes, não-ligantes, hibridizações sp (e até na equação de Schroedinger!), mas depois não fazem a mínima ideia de como prever a estrutura ou a fórmula molecular do sulfureto de sódio. É claro que não entendem nada daqueles conceitos. Decoram só umas tantas palavras que não podem de forma alguma entender. É como se um aluno aparecesse a falar em cálculo Laplaciano, mas depois não soubesse resolver $3 x+5=7$ ! $O$ objectivo deve ser treinar bem os alu- nos a visualizarem esquemas simples como

\section{$|\mathrm{N} \equiv \mathrm{N}| \quad \underline{\mathrm{O}}=\underline{\overline{\mathrm{O}}}$}

e daí tirarem a fórmula molecular e algumas propriedades, e não o de ensinar aquelas ligações químicas já a um nível com alguma profundidade (como se faz no $12^{\circ}$ ano) mas, precisamente porque essa "profundidade" não assentou em bases sólidas, tudo vai por água abaixo e o aluno nunca mais será capaz de, compreendendo, escrever os diagramas do $\mathrm{N}_{2}$ e do $\mathrm{O}_{2}$. Eu tenho testado isso mesmo nas minhas aulas! Que interessa ensinar as "excepções à regra do octeto", se depois eles não sabem aplicar a dita regra? Faz-me lembrar os alunos que decoravam as excepções às regras gramaticais do francês, mas depois não eram capazes de minimamente se fazerem entender em francês! Algo de similar se passa com o conhecimento das ligações químicas por parte dos alunos.

2.4. A ligação metálica talvez seja mais fácil de ensinar em termos elementares. Pese embora a complexidade que lhe é característica, parece-me muito simples e útil dar o caso do sódio metálico, dizer que "tudo se passa" como se um conjunto de átomos - Na se comportasse como um conjunto de $\mathrm{Na}^{+}$mergulhados num fluxo electrónico comum. Normalmente não necessitamos de fazer uma representação gráfica de tal estrutura mas, para efeitos didácticos, não me parece que haja mal em representá-la como na fig. 11.32, pág. 470 de R. Chang [4], ou na fig. 1.18.1, pág. 145 de V. Lobo [5], isto é, um conjunto de cargas positivas rodeadas de cargas negativas comuns a todas as positivas. O que é útil é mostrar como a partir desta imagem podemos prever que a tal estrutura conduza bem a electricidade, ao contrário da estrutura

$$
\mathrm{Na}+|\overline{\mathrm{Cl}}|-
$$


que, por ter os electrões rigidamente adstritos aos átomos a que "pertencem", não deverá conduzir a corrente eléctrica; seja maleável, pois aqueles núcleos podem facilmente rodar uns sobre os outros; etc.

\section{CONCLUSÕES}

- Entendo que é muito importante que alunos e profissionais de química sejam capazes de visualizar os diagramas de Lewis dos compostos químicos comuns, para melhor preverem e entenderem as suas características.

- É possível fazer esse ensino a um nível elementar, utilizando um modelo muito simples.

- Os alunos devem depois ser conduzidos a praticar extensivamente esse modelo simples. Só depois dessa boa prática e depois de um ensino dos aspectos gerais mais relevantes da química já com alguma extensão, é que se deve proceder a um ensino da ligação química a um nível mais elevado. Naquele ensino de química dever-se-ia estar sempre a recorrer aos diagramas de Lewis, como ajuda interpretativa dos fenómenos ensinados [por exemplo, na cinética química, na solvatação (ou só hidratação) e ionização de compostos tais como $\mathrm{NaCl}$ e $\mathrm{HCl}$, na auto-ionização de solventes como $\mathrm{H}_{2} \mathrm{O}$ ou $\mathrm{NH}_{3}$, reacções de ácido base, de complexação, de eléctrodo, de radicais livres, na acção venenosa do $\mathrm{CO}$ ou do $\mathrm{AsH}_{3}$, na química orgânica, etc., etc., etc.]. Só depois destas bases de química bem entendidas, é que faz sentido passar a um estudo mais desenvolvido da ligação química. De contrário, "tudo cai em saco roto". Seria como tentar ensinar a geometria de Riemann ou a de Lobatschevsky a quem, da geometria de Euclides, ainda não percebeu bem o que são rectas paralelas ou perpendiculares, o que é um triângulo ou um quadrado, ou como se calcula a sua área. Pareceme que é algo parecido com isso que se anda a fazer no ensino do $12^{\circ}$ ano de química. Dá-se tanto de ligação química a quem não sabe fazer um diagrama de Lewis das mais simples moléculas, ou interpretar a corrosão de um pedaço de ferro, ou perceber a diferença entre um álcool e um ácido orgânico!

\section{AGRADECIMENTOS}

Agradeço a todos os meus Mestres, desde o professor de instrução primária (meu Pai), até ao meu Supervisor de Doutoramento (Dr. John Newton Agar).

\section{* Departamento de Química, Universidade de Coimbra, 3049 Coimbra, Portugal e-mail<fcamvmml@gemini.ci.uc.pt>}

\section{REFERÊNCIAS}

1. Galardoado pelo Presidente da República com a Medalha de Grande Oficial da Ordem Militar de Santiago de Espada pelos seus elevados méritos como Professor.
2. Presto a minha homenagem ao Professor Doutor Cotelo Neiva, meu professor do Curso Geral de Mineralogia e Geologia do $1^{\circ}$ ano de Engenharia Química, por me ter feito compreender, numa aula, o significado dos modelos com uma frase, "... para este assunto [certos aspectos da mineralogia] basta-nos o átomo de Bohr ...". Aí me apercebi de que não faz sentido dizer se o "átomo de Bohr" está certo ou errado. É somente um modelo cuja utilidade pode ser maior ou menor, consoante o caso da sua aplicação. E para o ensino elementar dos diagramas de Lewis esse modelo basta.

3. Por "composição e estrutura" entende-se, neste contexto, a estequiometria da molécula e uma primeira ideia sobre as posições relativas dos átomos e sobre a natureza da ligação que os une. É óbvio que este texto não pretende ser o do manual de estudo para os alunos, mas somente as linhas básicas do modo de ensino (oral e escrito) deste assunto. Como se disse, ele pressupõe o conhecimento do "átomo de Bohr" e da maneira como a tabela periódica indica os electrôes do último nível energético.

4. R. Chang, Chemistry, 4th Edition, McGraw-Hill, New York (1991).

5. V.M.M. Lobo, Noçōes Elementares de Química, Vol. 1. Serviço de Textos da Universidade de Coimbra (1979).

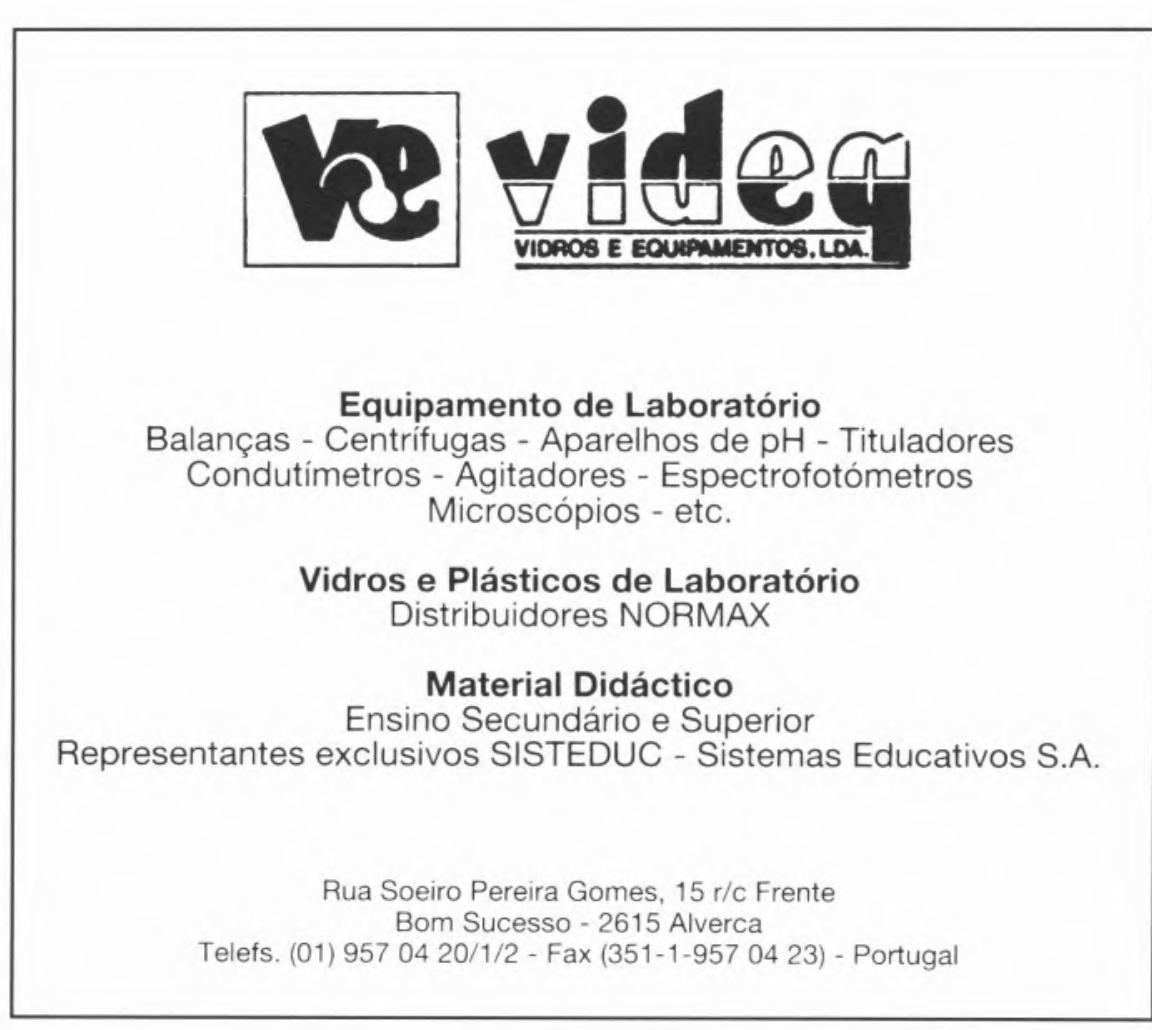

